\title{
Protección social para los pobres en América Latina
}

\section{Norman Hicks \\ nhicks@worldbank.org}

\section{Quentin Wodon}

qwodon@worldbank.org

Banco Mundial
Confrontados con perturbaciones macroeconómicas recurrentes, los gobiernos de América Latina y el Caribe se han preocupado cada vez más de establecer o fortalecer sistemas de protección social y programas de redes de seguridad. El objetivo de estos programas es contribuir a mitigar el impacto de tales perturbaciones (shocks) sobre los pobres antes de que ocurran, y ayudar a los pobres a enfrentarlas una vez que han ocurrido. Este artículo se centra en las redes de seguridad financiadas o prescritas por el sector público que funcionan como mecanismos para enfrentar riesgos, examina las características de una red de seguridad satisfactoria, comparando los principales tipos de redes de seguridad que existen actualmente, y en general concluye que ningún programa satisface todos los criterios de eficiencia y eficacia, aunque algunos son mejores que otros. Por último, ¿se ha logrado verdaderamente proteger a los pobres mediante la focalización del gasto público durante las crisis? El artículo observa que debido a las restricciones fiscales que impone una crisis, el gasto social suele ser procíclico cuando en teoría debería ser anticíclico. Lo paradójico es que el propio gasto en protección social no parece estar protegido. 


\section{El contexto: pobreza persistente y vulnerabilidad}

\section{a las perturbaciones macroeconómicas}

La región de América Latina y el Caribe ha estado plagada de perturbaciones macroeconómicas durante los veinte últimos años, con graves consecuencias para los pobres (véanse Glewwe y Hall, 1998; Lustig, ed., 1995; Lustig, 1999; Ganuza, Taylor y Morley, 1998). Tales perturbaciones han sido de las llamadas "covariantes" (Holzmann y Jorgensen, 1999), que afectan el ingreso real de gran parte de la población, habitualmente por la reducción tanto del salario real por hora (vía inflación) como del número de horas trabajadas (vía desempleo o subempleo). Aparte de estos efectos sobre el ingreso que pueden disiparse una vez que se reanuda el crecimiento, las perturbaciones macroeconómicas pueden tener también consecuencias a más largo plazo. Por ejemplo, la reducción de la cantidad y calidad de la atención de salud pública debido a recortes presupuestarios durante una crisis puede generar un daño irreparable. Asimismo, para enfrentar una crisis, los padres tal vez envíen a sus hijos a trabajar para compensar su propia pérdida de ingresos. Si se sustituye la escolaridad por el trabajo infantil, y si los niños no regresan a la escuela en una etapa ulterior, incurrirán en una pérdida salarial de largo plazo debido a su menor dotación de capital humano (Wodon y Siaens, 2000). Todo esto contribuiría a explicar por qué De Janvry y Sadoulet (1999) hallan pruebas de que el incremento de la pobreza que sigue a una perturbación macroeconómica puede ser mayor que la reducción ulterior de la pobreza con el crecimiento.

CUADRO 1

América Latina y el Caribe: Número de pobres e indigentes, 1986-1998

\begin{tabular}{lccccc}
\hline Año & $\begin{array}{c}\text { Población } \\
\text { (millones) }\end{array}$ & $\begin{array}{c}\text { Porcentaje de } \\
\text { población pobre }\end{array}$ & $\begin{array}{c}\text { Número de pobres } \\
\text { (millones) }\end{array}$ & $\begin{array}{c}\text { Porcentaje de } \\
\text { población indigente }\end{array}$ & $\begin{array}{c}\text { Número de indigentes } \\
\text { (millones) }\end{array}$ \\
\hline 1986 & 407.38 & 33.75 & 137.49 & 13.32 & 54.26 \\
1989 & 430.98 & 38.26 & 164.89 & 17.59 & 75.81 \\
1992 & 454.65 & 39.65 & 180.27 & 18.65 & 84.79 \\
1995 & 478.21 & 36.92 & 176.56 & 15.94 & 76.23 \\
1996 & 486.06 & 36.74 & 178.58 & 16.10 & 78.26 \\
1998 & 501.87 & 35.83 & 179.84 & 15.55 & 78.05 \\
\hline
\end{tabular}

Fuente: Wodon (2000a). Las cifras de pobreza correspondientes a 1998 están basadas en proyecciones, no en encuestas.

$\square$ El presente artículo fue preparado para el XII Seminario Regional de Política Fiscal en Chile, celebrado en enero de 2000. El artículo está basado, en parte, en el último capítulo de un estudio regional sobre pobreza y políticas (Wodon, 2000a) completado con financiamiento de la Oficina Regional para América Latina y el Caribe del Banco Mundial (Economista en Jefe, Guillermo Perry). Los autores agradecen la valiosa colaboración de Ana María Arriagada, Judy Baker, Charles Griffin, Margaret Grosh, Kathy Lindert y William Maloney. Las opiniones vertidas en este artículo corresponden a los autores, y no representan necesariamente las del Banco Mundial, sus Directores Ejecutivos o los países que representan.
Hay indicios de que las reformas promulgadas en muchos países de la región en los años noventa han estado dando al menos algun os frutos. Wodon (2000a) estima que en 1996 poco más de un tercio de la población regional (36.7\%) era pobre (es decir, no podía sustentar sus necesidades alimentarias y no alimentarias esenciales), y una de cada seis personas (16.1\%) era indigente (o sea, no podía sustentar sus necesidades alimentarias esenciales). Esto representa un progreso comparado con 1992, cuando las incidencias de la 


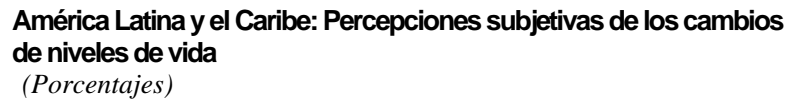

\begin{tabular}{|c|c|c|c|c|}
\hline & Mejor & Igual & Peor & No responde \\
\hline $\begin{array}{l}\text { Tomando todo en consideración, ¿diría usted que sus padres vivían mejor, igual } \\
\text { o peor que como usted vive hoy? }\end{array}$ & 61.2 & 22.0 & 14.4 & 2.4 \\
\hline $\begin{array}{l}\text { Y respecto a sus hijos, ¿cree usted que ellos vivirán mejor, igual o peor que } \\
\text { como usted vive hoy? }\end{array}$ & 46.1 & 20.7 & 22.0 & 11.2 \\
\hline
\end{tabular}

Fuente: Encuesta de 1999 del Wall Street Journal, citada por Rodrick (1999).

pobreza y la indigencia eran mayores. Sin embargo, el número absoluto de pobres no se ha reducido de la misma manera debido al crecimiento de la población. Además, si la comparación se establece con 1986 en vez de 1992, se advierte que las cifras de pobres e indigentes se han elevado considerablemente en 1996 (véase una encuesta de estimaciones de pobreza en Lustig y Arias, por publicarse). Las proyecciones de una reducción ulterior de la pobreza entre 1996 y 1998, utilizando elasticidades de la reducción de la pobreza respecto al crecimiento y los niveles reales de crecimiento observados en la región, sugieren sólo avances limitados en términos porcentuales, mientras que las cifras de pobres e indigentes permanecen constantes. ${ }^{1}$

Además de sufrir altos niveles de pobreza, los hogares latinoamericanos están afectados por la inestabilidad del ingreso y el empleo. Aunque suele pensarse que el nivel de inestabilidad está vinculado con las tendencias actuales hacia la globalización, De Ferranti, Perry y otros (2000) demuestran que la inestabilidad no ha crecido con el tiempo, y que ella no es peor en América Latina que en otras regiones en desarrollo. No obstante, hay mucha más inestabilidad en América Latina que en los países de la OCDE y la apertura puede haber provocado un aumento de las diferencias salariales entre los trabajadores más calificados y menos calificados. ${ }^{2}$ Además, aunque los cambios actuales en los mercados laborales deberían acarrear en definitiva ganancias agregadas netas positivas, pueden inducir perturbaciones idiosincrásicas (es decir, propias de los

\footnotetext{
${ }^{1}$ La región ha mostrado un mejor desempeño en términos de los indicadores no monetarios de bienestar, registrándose progresos en materia de analfabetismo adulto, mortalidad infantil, esperanza de vida, matrícula bruta en la enseñanza secundaria y acceso al agua potable.

${ }^{2}$ Falta un núcleo convincente de datos empíricos sobre muchos de estos temas. Lustig y Arias (por publicarse) sostienen, por ejemplo, que la rentabilidad de las especializaciones se ha venido ampliando, pero Gill (1999) insinúa que los datos empíricos son todavía poco claros. Véase, por ejemplo, Fajnzylber y Maloney (1999).
}

hogares) en los individuos que pierden sus empleos en un momento en que la región no ha desarrollado todavía plenamente sus sistemas de protección social.

En estas circunstancias, no es de extrañar que haya cierto malestar en la región. Aunque el nivel medio del ingreso per cápita se ha elevado en la mayoría de los países latinoamericanos y caribeños en los años noventa, al parecer esto no se ha traducido aún en un mejoramiento de la percepción subjetiva de bienestar. El cuadro 2 presenta los resultados de una encuesta de opinión en 1999 realizada por el Wall Street Journal en catorce países de América Latina y el Caribe. Casi dos tercios de los encuestados creen que sus padres llevaban una vida mejor que ellos. Menos de la mitad cree que sus hijos tendrán una vida mejor que ellos. Este pesimismo refleja probablemente tanto una sensación de inseguridad económica como la falta relativa de progreso en reducir la pobreza observada en las dos últimas décadas y documentada más atrás.

No hay respuestas fáciles para los problemas e incertidumbres que encaran los hogares pobres de América Latina y el Caribe. Las políticas macroeconómicas que promueven el crecimiento económico estable y generalizado contribuyen por cierto a reducir la pobreza, pero no son suficientes. Los gobiernos de la región se han preocupado cada vez más de establecer o fortalecer sistemas de protección social y programas de redes de seguridad que contribuyan a mitigar el impacto potencial de las perturbaciones económicas antes de que ocurran y ayudar a los pobres a enfrentarlas una vez que han ocurrido. En este artículo, que se centra en las redes de seguridad financiadas o prescritas por el sector público que funcionan como mecanismos para enfrentar riesgos, se plantean algunos interrogantes. ¿Cuáles son las características de una buena red de seguridad pública? ¿Cuáles son los tipos principales de redes de seguridad que existen actualmente en los países de la región? ¿Qué programas 
deben protegerse o ampliarse durante las crisis económicas? Por último, ¿se ha protegido realmente a los pobres mediante el gasto público focalizado durante las crisis? Las respuestas que se entregan aquí son provisionales. La sección II del artículo presenta al lector los conceptos principales empleados en la literatura sobre protección social y redes de seguridad en el contexto de las diversas formas en que los hogares son afectados por las perturbaciones económicas o responden a ellas. La sección III muestra los tipos principales de programas que existen actualmente, con sus fortalezas y debilidades. La sección IV utiliza datos sobre siete países latinoamericanos para evaluar el resultado real de proteger a los pobres mediante redes de seguridad durante las crisis. Y la sección V pone fin al artículo con una conclusión somera.

\section{II}

\section{El objetivo: diseñar redes de seguridad y sistemas de protección social operantes}

Un estudio reciente sobre la estrategia de protección social (Banco Mundial, 1999) sitúa tal protección en el contexto del manejo del riesgo social (al respecto véase también Holzmann y Jorgensen, 1999). Plantea dividir las estrategias de manejo del riesgo social en tres tipos: reducción del riesgo, alivio del riesgo y enfrentamiento del riesgo. En la reducción del riesgo intervienen la gestión macroeconómica, las regulaciones y las políticas de desarrollo institucional que contribuyen a evitar que las crisis ocurran. Aunque estas políticas de prevención tienen importancia, son demasiado genéricas como para formar parte del sistema de protección social que consiste principalmente en estrategias de alivio y enfrentamiento. Las estrategias de mitigación del riesgo se anticipan a la perturbación para poder reducir su impacto una vez que se ha producido. Incluyen, por ejemplo, la diversificación del ingreso y los mecanismos de seguros, tanto formales como informales. Las estrategias para enfrentar el riesgo se aplican después de la perturbación, para ocuparse de los impactos no cubiertos por las políticas de mitigación. Gill (1999) ofrece una síntesis de algunas de las principales políticas de manejo del riesgo socioeconómico que aplican el gobierno y el sector privado en la región (cuadro 3).

\footnotetext{
${ }^{3}$ Varios autores han revisado últimamente la literatura sobre protección social, redes de seguridad y crisis. Entre otros, Klugman (1999) se ocupó de las redes de seguridad, Dar y Tzannatos (1999) de los programas activos sobre el mercado laboral, Karni (1999) del seguro de desempleo, y Ezemenari y Subbarao (1999) de la asistencia social. El Banco Interamericano de Desarrollo (en febrero de 1999) y el Banco Mundial (en junio de 1999) han realizado conferencias sobre estos temas. Véase también en De Ferranti, Perry y otros (2000) un análisis de la protección social dentro del contexto de la globalización.
}

En este artículo nos centramos en los instrumentos provistos o prescritos por el sector público para ayudar a los individuos a enfrentar las perturbaciones (las últimas cuatro medidas de la columna central del cuadro 3). Esto no significa que no tomemos en cuenta las estrategias privadas de esta índole. ${ }^{4}$ Naturalmente que hay vínculos entre las estrategias públicas y privadas (sobre las transferencias véase por ejemplo Ezemenari, 1997). Como se mencionó en la introducción, algunas estrategias privadas de corto plazo pueden tener efectos permanentes que dificulten la reducción de la pobreza en el largo plazo. Es lo que ocurre cuando se resiente la nutrición de algunos miembros de la familia, o si los niños son retirados de la escuela para ponerlos a trabajar. ${ }^{5}$ En términos más generales,

\footnotetext{
${ }^{4}$ Para enfrentar las pérdidas de ingresos inducidas por perturbaciones, los pobres adoptan una amplia variedad de estrategias: cambiarse de empleo del sector formal al informal; trabajar más horas y/o trabajar en un segundo empleo; promover la participación en la fuerza laboral de otros miembros de la familia como cónyuges e hijos; vender (o consumir en el caso de los agricultores) activos productivos y de otra índole, incluidas las existencias; migrar temporal o permanentemente en búsqueda de oportunidades de empleo; reducir los patrones de consumo, lo que incluye restringir la ingesta alimentaria de los miembros de la familia, retirar a los niños de la escuela para reducir el gasto en educación, o postergar el gasto en salud; reubicar y/o reestructurar los hogares, por ejemplo, haciendo que varias familias vivan bajo un mismo techo; recurrir a la ayuda extrafamiliar tanto en especie como en efectivo, de las comunidades locales, amigos y parientes, y de instituciones privadas como las ONG (esto destaca a su vez el papel del capital social). Cunningham (1998) ofrece un interesante estudio sobre la dimensión de género de estas estrategias.

${ }^{5}$ Aunque los efectos de sustitución entre trabajo y escolaridad tienden a ser parciales debido a la posibilidad de que los padres reduzcan el tiempo que los hijos dedican al esparcimiento (Ravallion y Wodon, 2000a), se ha estimado respecto de seis países latinoamericanos que en promedio la reducción de la probabilidad de que un
} 


\begin{tabular}{|c|c|c|}
\hline Indole de la medida & Gobierno & Sector privado \\
\hline $\begin{array}{l}\text { Principalmente prevención } \\
\text { (reducción del riesgo) } \\
\text { Reguladora } \\
\text { O financiada por los contribuyentes } \\
\text { Universal }\end{array}$ & $\begin{array}{l}\text { Políticas macroeconómicas } \\
\text { Reglamentos financieros } \\
\text { Inversiones en infraestructura } \\
\text { Reglamentación laboral conexa } \\
\text { Inversiones en capital humano }\end{array}$ & $\begin{array}{l}\text { Inversiones en infraestructura } \\
\text { Inversiones en capital humano } \\
\text { Diversificación de carteras }\end{array}$ \\
\hline $\begin{array}{l}\text { Principalmente asistencia } \\
\text { (enfrentamiento del riesgo) } \\
\text { Transferencias dentro del período } \\
\text { Financiada por los contribuyentes } \\
\text { Focalizada: centrada en los pobres }\end{array}$ & $\begin{array}{l}\text { Programas de obras públicas } \\
\text { Transferencias en efectivo sujetas a } \\
\text { verificación de medios } \\
\text { Transferencias en efectivo condicionales } \\
\text { Transferencias en especie }\end{array}$ & $\begin{array}{l}\text { Transferencias entre hogares } \\
\text { Solidaridad comunitaria } \\
\text { Apoyo de las organizaciones no } \\
\text { gubernamentales (ONG) } \\
\text { Sociedades públicas-privadas }\end{array}$ \\
\hline
\end{tabular}

Fuente: Gill (1999).

los programas de protección social y redes de seguridad financiados o prescritos por el sector público representan una tentativa de proteger a los pobres contra los riesgos emanados de perturbaciones exógenas o endógenas, covariantes o idiosincrásicas. Cabe recordar que una crisis económica produce una perturbación covariante, que afecta a mucha gente simultáneamente. Pero incluso en épocas normales, los hogares pueden sufrir perturbaciones idiosincrásicas, como una muerte, una enfermedad o la pérdida del empleo. Hay que distinguir entre las redes de seguridad social que deben funcionar en todo momento para ocuparse de las conmociones idiosincrásicas y los programas que están diseñados específicamente para ayudar a un gran número de personas pobres que sufren perturbaciones covariantes adversas de carácter transitorio (Banco Mundial, 1999).

Se suele disponer de más mecanismos para enfrentar las perturbaciones idiosincrásicas que las

niño vaya a la escuela cuando está desempeñando un trabajo remunerado fluctúa entre $21 \%$ y $67 \%$, según la muestra (Wodon y Siaens, 2000; las estimaciones incluyen factores correctivos para una amplia gama de otras variables que inciden en la decisión de ir a la escuela y/o a trabajar, de modo que son efectos marginales netos). Esta sustitución entre trabajo y escolaridad reduce la dotación de capital humano de los niños que trabajan, pues cabe esperar que estos niños pierdan en promedio un $7 \%$ de sus remuneraciones actualizadas de toda la vida, incluso después de tomar en cuenta sus ingresos positivos cuando trabajaron de niños y la mayor experiencia acumulada al haber trabajado a temprana edad. Por cierto que la magnitud de las pérdidas de largo plazo debidas al trabajo infantil hace imperativo diseñar programas que ayuden a los padres a mantener a sus hijos en la escuela, especialmente durante las crisis económicas. covariantes, y las implicaciones fiscales de unas y otras son claramente distintas. Sin embargo, incluso entre los programas diseñados para ocuparse de las covariantes es posible identificar varias alternativas. Estas incluyen:

- programas de empleo de emergencia a través de obras públicas, que suelen utilizar métodos intensivos en mano de obra, considerados habitualmente de asistencia laboral;

- fondos sociales que crean programas especiales, habitualmente en las zonas rurales, para financiar obras públicas en pequeña escala identificadas por grupos comunitarios locales;

- intervenciones nutricionales y alimentarias, sobre todo las focalizadas en grupos vulnerables, como niños y mujeres embarazadas. Pueden adoptar muchas formas, que incluyen distribución de alimentos, cupones para adquirir alimentos y alimentación servida en escuelas o cocinas comunitarias;

- sistemas de bonificaciones directas en efectivo focalizadas en los más pobres, que pueden estar condicionadas a determinadas conductas (asistencia a la escuela y/o visitas al centro de salud);

- otros instrumentos, como pensiones y seguro de desempleo, que incluyen sistemas de indemnización obligatoria por cese en el trabajo.

Otra manera de organizar el análisis es considerar los programas según los grupos etarios a los que sirven, puesto que los distintos grupos de edades tienen 
necesidades diferentes. ${ }^{6}$ Los grupos más jóvenes corren generalmente un mayor riesgo nutricional, mientras que para los adultos el problema principal sería el empleo. Para los ancianos, lo esencial es mantener un ingreso suficiente para satisfacer las necesidades esenciales y tener un acceso adecuado a la atención de salud.

Actualmente, casi todos los países latinoamericanos y caribeños tienen, en diversa medida, alguna combinación de los programas descritos. Sin embargo, son muy pocos los programas que cumplen cabalmente con los criterios de una red de seguridad ideal. Tal red debería tener las siguientes características: ${ }^{7}$

- estar basada en un análisis acabado de quiénes tienden a verse más afectados por las crisis, y qué clase de mecanismos utilizan normalmente los afectados para enfrentarlas;

- ofrecer una cobertura suficiente de la población a la que se desea llegar, sobre todo los grupos más vulnerables y excluidos;
- estar bien focalizada en los pobres, con reglas claras en materia de elegibilidad y cese, de manera que el acceso sea simple y predecible;

- hallarse bajo la supervisión de instituciones ya establecidas y que funcionen bien;

- $\quad$ ser anticíclica (es decir, recibir más financiamiento cuando hay una crisis económica), y en algunos casos aplicarse automáticamente cuando se den factores desencadenantes previamente convenidos, como un aumento del desempleo o un incremento de la pobreza sobre cierto nivel;

- $\quad$ ser sustentable desde el punto de vista fiscal;

- poder entregar beneficios con rapidez, y lograr que la mayor parte posible de los costos vaya a incrementos netos del ingreso;

- complementar, y no sustituir, los programas de redes de seguridad y otros mecanismos de protección social de carácter privado;

- reducirse proporcionalmente una vez pasada la crisis.

\section{III}

\section{Los instrumentos: tipos de redes de seguridad y programas de protección social}

\section{Programas de asistencia laboral}

Los programas de asistencia laboral dan empleo mediante proyectos de obras públicas diseñados específicamente. El ejemplo clásico es Trabajar, en Argentina. En este programa, los proyectos son identificados por los gobiernos locales, las oNG y los grupos comunitarios, y puede ofrecer empleo por no más de 100 días por participante. Los anteproyectos son revisados por un comité regional, y se favorecen aquellos con mayor impacto sobre la pobreza y el empleo. ${ }^{8}$

\footnotetext{
6 Idea aportada por Ana María Arriagada. Para detalles, véase el Apéndice.

7 Véase un análisis más acabado de los criterios en Grosh (1995).

${ }^{8}$ En una reforma reciente de Trabajar se tomaron varias medidas para mejorar el rendimiento del programa. La reforma se centró en incrementar la participación y financiamiento comunitarios en la elección de los proyectos susceptibles de financiarse. Trabajar opera ahora en colaboración con los grupos comunitarios locales, las ONG y las municipalidades que presentan proyectos. Los proyectos tienen que ser aprobados primero en cuanto a su viabilidad técnica. A continuación, son seleccionados conforme a un puntaje. Se otorga más puntaje a los proyectos situados en las zonas más pobres, que rinden mayores beneficios públicos, que son patrocinados por
}

Los trabajadores contratados para un proyecto son pagados por el gobierno, concretamente por el Ministerio del Trabajo. Los demás costos son financiados por las autoridades locales. Ejemplos de proyectos elegibles comprenden la construcción o reparación de escuelas, instalaciones sanitarias, instalaciones de saneamiento básico, pequeñas carreteras y puentes, cocinas y centros comunitarios, y presas y canales pequeños.

grupos comunitarios u oNG prestigiados, y que reducen los costos laborales por debajo del salario mínimo. Estas nuevas características han mejorado la focalización tanto a nivel geográfico como individual. La participación de los grupos locales ha mejorado también la calidad de la supervisión y la retroalimentación de los proyectos.

${ }^{9}$ Estas actividades son bastante similares a las financiadas por los fondos sociales (véase más adelante). Una de las diferencias entre un proyecto de fondo social y un proyecto de asistencia laboral es que este último tiende a ser supervisado por las autoridades locales y no por organismos independientes, y que la ejecución no suele contratarse con el sector privado, sino que la llevan a cabo los organismos patrocinadores, que pueden ser gobiernos locales o provinciales, grupos privados u organizaciones nacionales. Otra diferencia es que los programas de asistencia laboral tienen como prioridad la generación de empleo e ingreso, mientras que los fondos sociales se centran más en la calidad de la infraestructura producida. 
Los proyectos financiados por Trabajar se circunscriben a zonas pobres identificadas conforme a un mapa de pobreza. Además, los salarios se fijan de manera que no superen el $90 \%$ del imperante en el mercado, de modo que los trabajadores tengan un incentivo para retornar a empleos del sector privado cuando éstos estén disponibles. Por lo tanto, además de la focalización geográfica, el programa entraña la autofocalización. En general, se ha informado que la focalización en los pobres en Trabajar II (la segunda ronda del proyecto) ha sido bastante buena, pues $75 \%$ de los fondos llegan al 20\% inferior de la distribución del ingreso, y $40 \%$ de ellos llega al 5\% inferior. No obstante, la oferta de empleos del programa depende tanto de las asignaciones presupuestarias como de la capacidad de las comunidades locales para identificar proyectos viables. Pese a todas sus bondades, Trabajar ha suministrado empleo a no más de $1 \%$ ó $2 \%$ de la fuerza laboral, en momentos en que el desempleo ha fluctuado entre $13 \%$ y $18 \%$ de la fuerza laboral.

El Gobierno de Chile también implementó programas masivos de asistencia laboral durante el período 1975-1988, con el fin de absorber a los trabajadores desplazados del sector público y reducir el desempleo durante el período de ajuste. Tal como Trabajar, estos programas daban empleo en obras públicas de emergencia, que incluían el mantenimiento y reparación de caminos y escuelas, la construcción de parques, proyectos de silvicultura, etcétera. Los programas eran administrados por las municipalidades, y llegaron gradualmente a su apogeo en 1983, cuando empleaban a un $13 \%$ de la fuerza de trabajo total (más de 500000 trabajadores), siendo la tasa de desempleo de $17 \%$. Los programas se redujeron gradualmente a medida que aumentaba el empleo en el sector privado, hasta suprimirse por completo en 1988. Los dos más grandes ofrecían trabajo manual a salarios muy bajos para asegurar la autofocalización. La mayoría de los trabajadores era no calificada, y recibían un cuarto del salario mínimo corriente de entonces (alrededor de la mitad del salario de mercado). Uno de cada cuatro participantes era una mujer. Sin embargo, aunque el programa se consideraba exitoso en términos de reducir la pobreza y el impacto social del desempleo, la calidad de las obras públicas producidas era notoriamente deficiente, y lo fue aún más al ampliarse el programa. Además, no es claro que todos los trabajadores del programa habrían quedado desempleados si éste no hubiera existido. Una evaluación concluyó que 32\% de los participantes carecía de experiencia laboral antes de participar en el programa, y $46 \%$ se había retirado voluntariamente antes de ingresar a él. Muchos de los que carecían de experien- cia eran mujeres que trabajaban por primera vez (Universidad de Chile, 1992).

Las ventajas de los programas de asistencia laboral son su capacidad de expandirse con rapidez durante una crisis una vez que se han establecido los mecanismos básicos, y de llegar a los pobres mediante la focalización por área, y dentro de las áreas pobres, mediante la autofocalización merced a los bajos salarios. Pero el problema de estos programas es que el costo de generar un dólar de ingreso adicional para los pobres por medio de las obras públicas suele ser elevado (algunos tres dólares o más). Para comprender por qué, conviene utilizar la medida de costo-eficacia y la descomposición de ella propuesta en el recuadro 1.

La medida de costo-eficacia que se utiliza es la proporción de los costos totales del programa que llega a los pobres mediante incrementos netos de los ingresos. Si se modifica ligeramente la fórmula propuesta por Ravallion (1999), como se indica en el recuadro 1 , cabe suponer que esta proporción es función de cuatro parámetros claves: el incremento salarial proporcional, el desempeño de la focalización, la participación salarial y el apalancamiento presupuestario. Un valor razonable del incremento salarial proporcional sería 0.5 , porque los salarios de asistencia laboral son bajos y los pobres suelen hallar alguna otra manera de generar recursos, por ejemplo, mediante el empleo informal a tiempo parcial cuando no tienen acceso a los programas. Debido a la autoselección involucrada y las prioridades otorgadas a las áreas pobres, un desempeño de la focalización en torno a 0.8 sería satisfactorio. La participación salarial puede obtenerse a menudo de los registros administrativos, multiplicando el número de días laborales que creó el programa por el índice salarial, y dividiendo esta cantidad por el costo total del programa. En muchos casos, la participación salarial no superará la cifra de 0.7 . Por último, cuando el programa está financiado casi por completo por el estado federal (aunque la selección del proyecto se haga en el plano local), el apalancamiento presupuestario es igual a uno (en el caso de Trabajar, hay apalancamiento presupuestario, pero aunque esto ahorra dinero al gobierno central, los gobiernos locales tienen que pagarlo de todos modos). La medida de costo-eficacia se obtiene multiplicando los diversos parámetros. ${ }^{10}$ Por lo tanto, lo

\footnotetext{
${ }^{10}$ En nuestros ejemplos ilustrativos, esta medida sería igual a $0.5 *$ $0.8 * 0.7=0.28$, en cuyo caso el costo total de generar un dólar de ingresos salariales adicionales netos para los participantes en el programa es 1/0.28=3.6 dólares. Véase en Jalan y Ravallion (1998) un ejemplo de los métodos econométricos que pueden utilizarse para medir con cierta precisión el beneficio salarial neto de los programas de asistencia laboral mediante las encuestas de hogares (es decir, el parámetro NWB/W).
} 


\section{Recuadro 1}

MEDición DEL COSTO-EFICACIA DE LAS OBRAS PÚBLICAS

Siguiendo a Ravallion (1999), supongamos que sin obras públicas, un individuo tiene la probabilidad $\mathrm{F}^{*}$ de hallar empleo a un salario de mercado $\mathrm{W}^{*}$. Los ingresos previstos son $\mathrm{F}^{*} \mathrm{~W}^{*}$. Con obras públicas, el individuo percibe el salario de obras públicas W. Si el individuo puede continuar la búsqueda de empleo privado o por cuenta propia mientras participa en las obras públicas, con la probabilidad $\mathrm{F}$ de encontrar dicho empleo, el salario previsto en obras públicas es $\mathrm{FW}^{*}+(1-\mathrm{F}) \mathrm{W}$. El beneficio salarial neto del programa para el trabajador es $\mathrm{NWB}=(1-\mathrm{F}) \mathrm{W}-\left(\mathrm{F}^{*}-\mathrm{F}\right) \mathrm{W}^{*}$. Si el trabajador obtiene indemnización por desempleo o asignación de subsistencia, el beneficio salarial se reduce a NWB=(1-F) W - $\left(\mathrm{F}^{*}-\mathrm{F}\right) \mathrm{W}^{*}-\left(1-\mathrm{F}^{*}\right) \mathrm{S}$. Si el costo del programa es $\mathrm{G}$ para el gobierno por trabajador empleado, una medida de costo-eficacia es la proporción del gasto público transferido a los trabajadores como ganancia salarial NWB/G. Esta medida puede descomponerse como sigue:

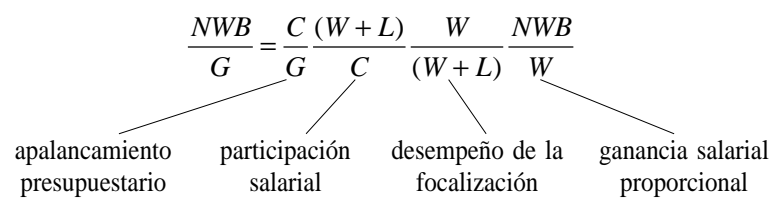

Los factores determinantes del costo-eficacia son: i) el coeficiente de apalancamiento $\mathrm{C} / \mathrm{G}$, donde $\mathrm{C}$ es el costo total por trabajador, incluido el financiamiento comunitario; ii) la participación salarial $(\mathrm{W}+\mathrm{L}) / \mathrm{C}$, donde $\mathrm{W}$ representa los salarios pagados a los pobres y L la filtración debida a los salarios pagados a los no pobres; iii) el desempeño de la focalización $\mathrm{W} /(\mathrm{W}+\mathrm{L})$ que es el porcentaje de salarios que llega a los pobres; y iv) la ganancia salarial proporcional NWB/W. Este modelo puede ampliarse para tomar en cuenta los beneficios de la infraestructura construida por las obras públicas, pero estos beneficios no son inmediatos (véase un modelo y un análisis en Wodon, 2000b).

habitual es que el gobierno nacional o federal gaste tres dólares o más para transferir un dólar a los pobres en salarios adicionales.

La noción de que cuesta tres dólares o más transferir un dólar de ingreso a los pobres mediante programas laborales podría cuestionarse, puesto que los beneficios podrían ser más altos por dos razones. ${ }^{11}$ Primero, el método presentado en el recuadro 1 no considera los beneficios de las propias obras públicas, que pueden ser sustanciales si los trabajadores son bien utilizados. No obstante, el problema es que estos beneficios se disfrutarán durante toda la vida útil de la infraestructura construida, mientras que lo que los pobres necesitan en tiempos de crisis es el refuerzo inmediato del ingreso. Si los pobres tienen tasas de descuento elevadas (que en general sí las tienen, pero sobre todo en épocas de crisis cuando sus recursos no proveen el sustento básico), el valor actualizado de los beneficios generados por las obras públicas puede ser

11 Véase un análisis más acabado de estos aspectos en Wodon (2000b) y Maloney (2000). bastante escaso. Además, puesto que el énfasis está en la creación de empleo y no en las inversiones, puede haber un sesgo hacia proyectos de prestigio o de trabajo ficticio que no serían muy valiosos. Esto sería particularmente válido en una crisis, cuando la rápida expansión del programa agota la reserva de proyectos viables.

Segundo, el método presentado en el recuadro 1 supone que para medir el impacto del programa sólo se debe tomar en cuenta el incremento salarial proporcional neto. Pero en períodos de alto desempleo, cabría sostener que al menos parte de la diferencia entre el salario de las obras públicas, y lo que el participante en el programa habría ganado por su cuenta sin el programa, estará disponible como ingresos para otro trabajador que no participa en el programa y que también está subempleado. En caso extremo, se podría tomar en cuenta todo el índice salarial en el análisis de costo-beneficio, lo que mejoraría considerablemente la relación costo-eficacia de tales programas.

Por otra parte, se podrían también aducir argumentos para sostener que las transferencias netas a los 
pobres son menore s de las que predice la descomposición en el recuadro 1. Por ejemplo:

Primero, dado que los trabajadores son pagados por las autoridades locales, las oportunidades de corrupción y sesgo político son más acentuadas. En Trabajar, persisten algunos indicios de influencias políticas en la elección de los participantes y de discriminación de género (se seleccionan pocas mujeres en algunas áreas).

Segundo, las comunidades más pobres no estarían siempre en buena posición para presentar propuestas de proyectos y/o contribuir a sufragar los costos no salariales. En este caso, el desempeño de la focalización del programa podría resentirse, porque la contribución de la focalización geográfica al desempeño global de la focalización se reduciría.

Además de Argentina y Chile, México también tiene una experiencia provechosa para evaluar las fortalezas y debilidades de los programas de asistencia laboral. En las zonas rurales de México el Programa de Empleo Temporal (PET) ofrece empleo fuera de temporada con un salario inferior al mínimo recurriendo a las obras públicas. El empleo es por un máximo de 88 días laborales con una remuneración equivalente al 90\% del salario mínimo. En 1999 se iban a crear 93 millones de días laborables y un millón de empleos. El PET es el ejemplo de un programa que funciona en épocas normales y no sólo durante las crisis, aunque está restringido a ciertos períodos del año solamente. Como era de prever, los proyectos hacen uso intensivo de mano de obra. Los ejemplos comprenden el riego de tierras, la pavimentación de caminos, el despeje de terrenos, el mejoramiento de viviendas y la instalación de sistemas de abastecimiento de agua y alcantarillado. Los datos sugieren una focalización satisfactoria: los participantes son pobres y necesitan los empleos temporales más que los no participantes porque no se benefician de ocupaciones que los mantengan empleados todo el año. No obstante, el programa no llega a las comunidades rurales más pequeñas (y tal vez las más pobres). En general, las comunidades PET casi duplican el tamaño de las comunidades no PET. Las comunidades PET tienen un mejor acceso que las comunidades no PET a la electricidad (74\% versus $60 \%)$, teléfonos públicos (33\% versus 19\%), enseñanza preescolar $(81 \%$ versus $67 \%)$, enseñanza primaria $(89 \%$ versus $82 \%)$ y enseñanza secundaria a distancia $(22 \%$ versus $11 \%$ ). Parte del problema puede deberse al costo más elevado (por ejemplo, administrativo) de llegar a las comunidades rurales muy pequeñas.

Cabría también considerar como red de seguridad los programas de capacitación laboral, en particular si pueden modificarse en épocas de crisis. En México, el programa Probecat se implementó en 1986 en respuesta al aumento del desempleo tras la crisis de la deuda de 1982 y las políticas ulteriores de ajuste estructural. Actualmente, el programa brinda capacitación a cerca de 500000 beneficiarios al año en las zonas urbanas. Una nueva evaluación del programa sugiere, no obstante, que no tiene un impacto estadísticamente significativo sobre el empleo y los salarios (Wodon y Minowa, 1999; véanse evaluaciones anteriores en Revenga, Riboud y Tan, 1994, y STPS, 1998). Estos resultados decepcionantes no son extraños, porque se ha visto que la mayoría de los programas de reconversión laboral en los países de la Organización de Cooperación y Desarrollo Económicos ( OCDE) han tenido impactos limitados. Uno de los motivos sería que la capacitación se imparte por un período demasiado breve (unos pocos meses) para entregar conocimientos que sean útiles a largo plazo. Algunos programas de capacitación laboral funcionarían de hecho como redes de seguridad, prestando alivio temporal a los desempleados con un mecanismo de autofocalización similar al de los programas de obras públicas puesto que los participantes suelen recibir sólo el salario mínimo. Probablemente es mejor elegir uno u otro objetivo (capacitación o protección social) y no tratar de alcanzar ambos con un solo programa.

\section{Fondos de inversión social}

Los fondos de inversión social ( FIS) fueron la respuesta original del Banco Mundial a las repercusiones sociales de los programas de ajuste, y algunos de los primeros (por ejemplo, el Fondo Social de Emergencia de Bolivia, creado en 1991) fueron diseñados fundamentalmente para dar empleo (Jorgensen, Grosh y Schacter, 1992). De hecho, los FIS se crearon, en parte, para evitar los problemas vinculados con los programas de obras públicas de emergencia (de asistencia laboral). Sin embargo, casi todos los FIS apuntan ahora a programas diseñados para suministrar infraestructura social en pequeña escala, sobre todo en las zonas rurales y pobres, a través de proyectos generados y ejecutados en el plano local. Por lo tanto, los fondos sociales no son redes de seguridad per se. Nótese que a diferencia de los programas de asistencia laboral, algunos fondos sociales también financian programas que no involucran la construcción o el mantenimiento, tales como programas de nutrición, asistencia técnica y microcrédito. Cuando hay trabajo de construcción involucrado, no es raro ver que los fondos 
sociales utilizan mano de obra calificada a la que se paga salarios de mercado. Esto obedece a que la calidad de la infraestructura construida se considera más importante que la provisión de empleo para los pobres. Este es el caso del fondo social de Honduras, que se originó a partir de la transformación de un programa de generación de empleo a comienzos de los años noventa, pero que actualmente no considera que la creación de empleo sea su prioridad principal. Por otra parte, la mayoría de los fondos sociales suelen estar dirigidos a zonas pobres mediante el uso de un mapa de pobreza (o, en algunos casos, mediante el uso de un mapa de necesidades básicas insatisfechas).

Aunque tanto los programas de asistencia laboral como los de los fondos sociales materializan proyectos en el sector público, hay diferencias importantes entre unos y otros. El fondo social financia los costos de material y la mano de obra de un proyecto, aunque parte de la mano de obra local podría ser donada como un aporte de la comunidad. Esto varía según los FIS y los países. El programa de asistencia laboral generalmente financia el costo de mano de obra de un proyecto en el plano nacional o federal, y solicita que los gobiernos u organismos locales sufraguen los costos de material. Por lo tanto, en los programas de asistencia laboral hay un claro incentivo para que el organismo local busque métodos de construcción y elija proyectos que hagan uso intensivo de trabajo. Dado que los proyectos de los FIS son licitados al sector privado, a menudo utilizan los métodos de construcción más modernos y con uso intensivo de capital, aunque en algunos casos los fondos sociales especifican los niveles mínimos de empleo que deben alcanzar en sus operaciones.

La mayoría de los fondos sociales son organismos independientes de los ministerios del ramo, adscritos a menudo a la oficina de la Presidencia de la República, la que examina y financia los proyectos presentados por las ONG, los gobiernos locales y otros agentes patrocinadores. Sus fortalezas comprenden la participación de la comunidad local y la capacidad de responder a las percepciones de las necesidades locales, especialmente en las zonas rurales donde el gasto normal del gobierno, a menudo, no llega a los pobres. Asimismo, los fondos sociales tienen una mejor capacidad para evitar la corrupción y los proyectos "de trabajo ficticio". Pero no la tienen tanto para crear redes de seguridad, y normalmente no se expanden durante una crisis para ofrecer más empleo. De hecho, la cantidad de empleo y generación de ingreso que suministran los fondos sociales ha sido tradicionalmente es- casa. Por ejemplo, una revisión de ellos determinó que 10 fondos importantes suministraban un empleo que, en general, era igual a sólo $4 \%$ de la fuerza laboral (Goodman, Morley y otros, 1997). Asimismo, se estimó que la contribución monetaria de los salarios era escasa, como también lo era el impacto sobre la reducción de la pobreza proveniente de los propios proyectos. Los fondos sociales son más aptos para mejorar la oferta de salud, educación y servicios básicos de infraestructura, y en algunos casos influyen sobre resultados como las tasas de matrícula escolar (con correspondencia entre edad y curso) o la incidencia de enfermedades (las evaluaciones recientes que utilizan datos a nivel del hogar corresponden a Pradhan, Rawlings y Ridder, 1998, para Bolivia, y ESA Consultores, 1999, para Honduras).

No obstante, una de las ventajas claras de los fondos sociales es que tienen organizaciones fuertes con sistemas relativamente idóneos para la gestión y supervisión de proyectos. Estas organizaciones pueden utilizarse en tiempos de crisis para suministrar redes de seguridad social. El fondo social existente en Honduras, por ejemplo, ha demostrado ser muy útil para orientar la asistencia de emergencia a las aldeas locales tras el huracán Mitch. Existe, por lo tanto, la posibilidad de trabajar con los fondos de inversión social para modificar sus operaciones durante una crisis, para que, por ejemplo, hagan mayor hincapié en proyectos con uso intensivo de mano de obra y se involucren en nuevas zonas muy afectadas. Por ende, es una buena idea identificar proyectos intensivos en mano de obra anticipándose a una crisis potencial, de modo que estén listos para ser financiados si llega a sobrevenir una crisis.

\section{Programas de nutrición y alimentación}

Los programas de nutrición y alimentación adoptan una variedad de formas. Subbarao, Bonnerjee y otros (1997) han identificado unos treinta países que utilizan políticas alimentarias con fines redistributivos. En estos países, los subsidios a los consumidores se utilizan con tanta frecuencia como los programas de alimentación y de trabajo por alimentos, y mucho más a menudo que el racionamiento alimentario y los cupones para la compra de alimentos. De hecho, muchos programas de asistencia laboral que ahora ofrecen salarios en efectivo partieron al comienzo como programas de "trabajo por alimentos". En cuanto a los programas de alimentación directa, éstos suministran alimentos a los necesitados mediante la entrega directa de alimentos no 
preparados provenientes de una bodega administrada por el programa, la entrega de alimentos preparados provenientes de una cocina comunitaria o la provisión de un almuerzo o desayuno a los niños en la escuela. ${ }^{12}$ Las evaluaciones de los programas nutricionales indican, en general, que sólo hay un mejoramiento exiguo y marginal de la nutrición comparado con el caso en que la familia recibe una bonificación en efectivo equivalente. Esto se debe a que las familias pueden sustituir sus propias compras por los alimentos gratuitos y utilizar gran parte del ahorro para otros fines. Sin embargo, aunque un programa alimentario tenga un efecto aproximadamente equivalente a una bonificación en efectivo, hay menos posibilidades de desviación de fondos, puesto que es menos probable que se haga mal uso del alimento que del dinero. Además, es más probable que los alimentos lleguen a la mujer y se empleen para mejorar el bienestar de la familia, mientras que es más probable que el efectivo lo utilice el hombre para actividades de menor prioridad. Una alternativa intermedia entre el efectivo y los alimentos son los cupones para la compra de alimentos. Estos cupones tienen la ventaja adicional de que no requieren un sistema complicado de almacenamiento y transporte de alimentos y que utilizan, a su vez, la red privada de distribución alimentaria ya existente. En Honduras, el programa de cupones para la compra de alimentos solía comprender también los medicamentos y los libros escolares. En Jamaica, este programa se introdujo en reemplazo de los subsidios alimentarios generales, y ha demostrado ser eficaz para aumentar el ingreso de los pobres (Grosh, 1992).

Una manera habitual de focalizar los programas alimentarios consiste en vincular la distribución con un programa de salud, en particular la atención de salud materno-infantil. Así, los alimentos sirven de incentivo para asistir al programa, y la educación nutricional puede servir para mejorar el uso de los alimentos que se entregan. Cabe recordar que la entrega de alimentos a las mujeres disminuye también las posibilidades de que se desvíen para venderlos en el mercado. Los programas alimentarios también pueden diseñarse para que sean autofocalizados, si los productos alimentarios que se entregan son los que consumen los pobres y no la clase media. En su defecto, la distribución de alimentos puede realizarse en centros situados en las

\footnotetext{
${ }^{12}$ Los programas de alimentación escolar son sumamente populares en América Latina. Véase, por ejemplo, Phillips, Sáenz y otros (1995) respecto a Honduras, Dall Acqua (1991) respecto a Brasil, y Jacoby y Politt (1996) respecto a Perú.
}

vecindades pobres. Tales enfoques permiten reducir la carga administrativa de focalizar los programas, pero aumentan la posibilidad de filtración a los no pobres. Los programas de almuerzo y desayuno escolar son también difíciles de focalizar en el plano individual si no se quiere estigmatizar de "pobres" a algunos estudiantes dentro de la escuela. En muchos países estos programas están dirigidos a escuelas de las zonas pobres, pero también son frecuentes los programas no focalizados de esta índole. Un beneficio de estos programas es el incentivo para mantener los niños en la escuela a fin de que los alimenten y mejorar sus capacidades de aprendizaje mientras permanecen en ella (véase en Wodon y Siaens,1999a, una evaluación del programa mexicano de desayuno escolar). Desde un punto de vista nutricional, los beneficiarios principales de los programas pueden, no obstante, ser otros miembros de la familia si los niños no se alimentan en casa porque los padres saben que recibirán su almuerzo escolar.

Los subsidios alimentarios son otra forma de ayudar a los pobres a reducir el costo de su canasta de consumo (Besley y Kanbur, 1988). Los subsidios alimentarios, previa verificación de medios de sustento, tienden a ser más eficaces que otros subsidios para reducir la desigualdad y elevar el bienestar. Respecto de México, por ejemplo, Wodon y Siaens (1999b) sugieren que los subsidios universales son inadecuados para reducir la desigualdad y mejorar el bienestar. Los autores comparan tres programas: el ahora difunto subsidio universal a la tortilla, un programa que ofrecía un kilo de tortilla gratis a los hogares con un ingreso inferior a dos salarios mínimos, y un programa de leche subvencionada, también sujeto a verificación de medios de sustento. Sus hallazgos principales fueron los siguientes:

- Los subsidios alimentarios son mejores que los subsidios no alimentarios. Los subsidios a los bienes de consumo básicos como la tortilla reducen la desigualdad, especialmente en las zonas urbanas, y mucho más que los subsidios a los servicios de utilidad pública como agua y electricidad. No obstante, los subsidios alimentarios generan distorsiones de precios y son costosos. Además, un subsidio universal a la tortilla es menos eficaz que lo que sería un subsidio similar generalizado a los ingredientes necesarios para confeccionarla, como la harina de maíz.

- Dentro de los subsidios alimentarios, los subsidios sujetos a verificación de medios de sustento son mejores que los universales. El impacto marginal sobre la desigualdad y el bienestar que se logra con los 
subsidios universales a la tortilla no se aproxima a las mejoras del bienestar que se obtienen con los subsidios sujetos a verificación de medios de sustento.

Con todo, los subsidios no representarían una inversión lógica y eficaz en función de los costos para reducir la pobreza. Los subsidios alimentarios y los sistemas de distribución de alimentos pueden desincentivar la oferta de mano de obra (Sahn y Alderman, 1995). Pueden ser mal focalizados, con una filtración considerable hacia los no pobres (Grosh, 1994; Cornia y Stewart, 1995). Y aunque hasta cierto punto es posible lograr una autofocalización al subsidiar los bienes que consumen en mayor cantidad los pobres que los no pobres, esto no es una panacea (Tuck y Lindert, 1996). Por lo tanto, ha habido una tendencia a reducir el financiamiento de los subsidios alimentarios a fin de financiar otros programas, por ejemplo, en México (Levy y Dávila, 1998).

\section{Transferencias en efectivo condicionales}

Dado que los alimentos son intercambiables por dinero, cabría sostener que los subsidios en efectivo son la manera más sencilla y directa de brindar una red de seguridad. El uso de subsidios en efectivo evita, además, las pérdidas de utilidades vinculadas con la ayuda en especie. En los países desarrollados, y algunos países latinoamericanos adelantados, los pagos en efectivo a determinados hogares están volviéndose paulatinamente más comunes. Los pagos en efectivo incondicionales y formas similares de asistencia social suelen focalizarse en la mujer con hijos dependientes, los discapacitados, los ancianos y aquellos incapaces de trabajar. Sin embargo, los problemas de focalización y control de los pagos en efectivo tornan problemático este enfoque en los países más pobres que carecen de buenos sistemas administrativos. Por ejemplo, en Bolivia, el programa Bonosol ofrecía una vez al año un subsidio en efectivo equivalente al pago de cuatro semanas de salario mínimo a los ciudadanos adultos. Lo atractivo del subsidio y la falta de mecanismos de selección o identificación condujo a abusos generalizados, como la duplicación de pagos y los pagos a no bolivianos.

Una alternativa atrayente es vincular los subsidios en efectivo con la asistencia a la escuela u otra conducta conveniente. Esto se ha introducido en diversa medida en países como Brasil (Bolsa Escola), Argentina (Beca Secundaria), México (Progresa) y Honduras (PRAF). ${ }^{13}$ Estos programas no son redes de seguridad propiamente tales, o al menos no fueron diseñados originalmente para funcionar como redes compensatorias durante las crisis. Sin embargo, los programas ofrecen beneficios importantes a los hogares en época de crisis, y estos beneficios pueden aumentarse durante una recesión en caso necesario. En otras palabras, tal como ocurrió con los programas de capacitación laboral y los fondos de inversión social, los programas existentes que ofrecen transferencias en efectivo condicionales pueden ampliarse y modificarse para que sirvan de redes de seguridad durante una crisis. En general, no obstante, los subsidios relacionados con la escuela ofrecen sólo una respuesta parcial a las situaciones de crisis, por el sólo hecho de que los programas están dirigidos a las familias con hijos escolares, de modo que algunos de los más pobres que no pueden enviar sus hijos a la escuela quedan excluidos.

Los programas de transferencias en efectivo condicionadas a la asistencia escolar reducen los costos de oportunidad que representa para los padres pobres mantener sus hijos en la escuela. Este costo de oportunidad es esencialmente la pérdida del salario infantil o del valor que reviste para los padres el trabajo doméstico que realizan los hijos y del que no pueden disfrutar si estos últimos asisten a la escuela. En muchos casos, es difícil estimar este costo de oportunidad de la escolaridad, y no es tan obvio que los subsidios tengan que ser iguales al costo de oportunidad que representa para los padres enviar sus hijos a la escuela (Ravallion y Wodon, 2000a). En efecto, es lógico suponer que los padres tienen un interés intrínseco en que sus hijos asistan a la escuela, ya sea por motivos altruistas, o por los beneficios futuros que brindan las transferencias intergeneracionales una vez que los hijos llegan a la edad adulta. Sin embargo, en algunos países el nivel de los subsidios condicionales parece ser elevado. En el caso del Programa de Educación, Salud y Alimentación (Progresa), en México, por ejemplo, para justificar el nivel relativamente alto de los subsidios del programa, se ha sostenido que aparte de ofrecer incentivos para acumular capital humano,

\footnotetext{
${ }^{13}$ El personal de Progresa está preparando una evaluación rigurosa del programa con el respaldo del Instituto Internacional de Investigaciones sobre Políticas Alimentarias. Los resultados preliminares están disponibles en Progresa (1999). El Instituto Internacional de Investigaciones sobre Políticas Alimentarias va a colaborar también en la evaluación del Programa de Asignación Familiar (PRAF) de Honduras, con un diseño que combina las intervenciones por el lado de la demanda y de la oferta.
} 
mejoran también la calidad de vida global de las familias. No obstante, habría maneras más eficaces en función de los costos para mejorar la calidad de vida de los beneficiarios del programa. Por otra parte, como lo demuestran Wodon, González y Siaens (2000), cuando el valor de los subsidios es bajo, las intervenciones en la escolaridad por el lado de la demanda podrían excluir a los más pobres. Se necesita más estudio para medir las múltiples compensaciones recíprocas involucradas.

¿A qué nivel de enseñanza deben otorgarse los subsidios? Esto dependerá de las características del país. En Brasil y Argentina los programas se centran en la escuela secundaria, puesto que éstos son los niños más susceptibles de ser retirados de la escuela durante una crisis. En Honduras, el programa apunta a los cuatro primeros años de la escuela primaria. En México, el programa cubre el término de la enseñanza primaria y el primer ciclo de la enseñanza secundaria. En Venezuela, el programa cubre la enseñanza primaria. En algunos casos estos programas están vinculados no sólo a la asistencia, sino también al rendimiento escolar, que incluye el paso al próximo curso. Aunque esto puede ofrecer incentivos valiosos, hay que asegurarse de que tales condiciones no excluyan a los más pobres, a los que les costaría más tener éxito en la escuela.

¿Cómo deben focalizarse los subsidios? La experiencia de Progresa es interesante (Skoufias, Davis y Behrman, 2000). El programa emplea un mecanismo de focalización en tres etapas. Primero, se seleccionan las localidades rurales pobres que van a participar. A continuación, se seleccionan las familias pobres dentro de las comunidades participantes mediante un análisis discriminante multivariado. Por último, las comunidades locales pueden revisar la selección hecha por funcionarios de Progresa y reclasificar las familias pobres como no pobres y viceversa. Este mecanismo de focalización es esencialmente lógico, y los resultados parecen ser satisfactorios. Un motivo de preocupación es que el nivel de participación comunitaria sigue siendo marginal. El proceso de focalización es centralizado, en parte porque se desea evitar interferencias políticas en la selección de los beneficiarios; no obstante, podrían desplegarse más esfuerzos para promover el papel de las comunidades en él. Otra cuestión conexa se refiere a la necesidad de focalización dentro de las comunidades pobres. Mientras mayor sea la proporción de pobres en una comunidad, menor será la necesidad de focalizar dentro de ella, especialmente si hacerlo tiene costos, no tanto en el plano administrativo sino más bien en términos de cohesión social (los que no ingresan al programa pueden envidiar a los que se benefician de él). En Honduras, donde se está modificando el programa en parte sobre la base de la experiencia de Progresa, se ha decidido brindar apoyo a todas las familias residentes en las comunidades pobres participantes. ${ }^{14}$

Los programas de transferencia en efectivo condicional pueden emplearse también para promover buenas prácticas sanitarias, incluida la consulta con los prestadores locales de servicios de salud. Esto ocurre en el caso de Progresa en México, donde las familias seleccionadas reciben una transferencia (tanto en efectivo como en especie mediante un complemento nutricional) para fines de salud, aparte de las transferencias relacionadas con la enseñanza. Es decir, Progresa tiene como objetivo efectuar una intervención coordinada en materia de educación, salud y nutrición, con la esperanza de que el impacto de todo el programa sea mayor que la suma de sus partes. Por cierto que, tanto en el caso de Progresa como de otros programas, cuando se trata de maximizar el impacto de las intervenciones escolares y/o de salud, es importante tener presente los aspectos del lado de la oferta. Por ejemplo, Progresa ha conseguido elevar la matrícula escolar y la asistencia a los centros de salud, pero esto ha provocado tensiones por el lado de la oferta. Se han tomado medidas para coordinar la acción de Progresa con la de otros ministerios, como los de educación y salud, pero tal vez se necesiten otras medidas para optimizar las intervenciones en el lado de la demanda y de la oferta.

\section{Seguro de desempleo y otros programas}

El seguro de desempleo es común en Europa y América del Norte, pero menos frecuente en América Latina, en parte por su alto costo. Por lo demás, la legislación laboral vigente en muchos países de América Latina y el Caribe dispone el pago de una indemnización por cese en el servicio que es función del número de años trabajados; normalmente, esto equivale aproximadamente a un mes de sueldo por año de

\footnotetext{
14 En caso de ser factible, es importante utilizar ponderaciones distributivas en la evaluación de la focalización de los programas sociales y otras intervenciones. Véase un análisis de esta especie, por ejemplo, en Ravallion y Wodon (2000b) y Wodon y Yitzhaki (2000).
} 
servicio, hasta cierto máximo. Esto puede complementarse con un plan de seguro de desempleo (como en Argentina y Brasil para los trabajadores del sector formal) en virtud del cual los aportes mensuales de las nóminas y/o del empleador dan derecho al trabajador a recibir un pago mensual durante un tiempo limitado, cuyo monto es lo bastante bajo como para reducir los efectos de desincentivo. Pero dado que en muchos países el sector formal constituye menos de la mitad de la fuerza laboral total, la cobertura del seguro de desempleo/pagos de indemnización dista de ser completa, y la exclusión de los sectores informal y rural significa que estos mecanismos no llegan a las zonas en que se hallan muchos de los pobres. El paso de un sistema de pago de indemnización a otro de seguro de desempleo podría ser beneficioso si redujera los costos laborales. Sin embargo, el seguro de desempleo puede crear también problemas de riesgo moral al subsidiar el desempleo (los programas de asistencia laboral, en cambio, subsidian el empleo). Un elemento importante en este caso es asegurar que la indemnización por desempleo no sea tan generosa como para desalentar la búsqueda de empleo. Por esto, hay que supervisar tanto el monto de los pagos como el tiempo durante el cual los trabajadores pueden recibirlos (véase una revisión de la experiencia de la OCDE con las rigideces del mercado laboral y el seguro de desempleo en Nickell, 1997).

Una alternativa mencionada con frecuencia es un sistema de cuentas de ahorro para el seguro de desempleo (CASDE), con arreglo al cual los trabajadores no recibirían "compensación" alguna al perder sus empleos, pero tampoco sufrirían "sanción" alguna por encontrar rápidamente un empleo. Cada trabajador empleado haría una contribución mínima fija obligatoria a su CASDE todos los meses, y podría hacer contribuciones voluntarias adicionales que superaran los niveles mínimos obligatorios. Al quedar desempleado, el trabajador tendría derecho a retirar un monto fijo máximo por mes de su CASDE (también se permitirían retiros por montos menores). Cuando su saldo quedara en cero, o estuviera en vías de agotarse, tendría derecho a recibir asistencia por desempleo. La asistencia por desempleo se financiaría mediante un impuesto que afectaría a todos los asalariados. Cuando los trabajadores jubilaran con un saldo positivo en su CASDE, podrían utilizarlo para complementar sus pensiones. En general, los trabajadores mismos desempeñarían un papel mucho mayor en financiar su propio apoyo durante los períodos de desempleo. La ventaja principal de las CASDE es que tienden a establecer correctamente los incentivos, sin crear distorsiones en el comportamiento de empleadores y empresas. Es decir, los fondos que saca un desempleado de su CASDE reducen directamente la riqueza personal del individuo en un monto equivalente, de modo que los individuos internalizan plenamente el costo de la indemnización por desempleo. Los sistemas CASDE no están exentos de riesgos, y es probable que se requieran intervenciones especiales para proteger a aquellos trabajadores que tienden a ser más jóvenes, más pobres y menos educados. Respecto a Chile, Castro-Fernández y Wodon (2000) sugieren que aunque el efecto redistributivo por dólar gastado en indemnizaciones por desempleo de un sistema basado en las CASDE sería tal vez menor que el impacto redistributivo del sistema de asistencia por desempleo vigente en el país, el componente complementario de asistencia por desempleo del sistema sería de todas maneras altamente redistributivo, y probablemente tendría una cobertura mucho mayor porque el valor de las indemnizaciones sería más alto.

Por último, cabe mencionar que hay varios otros tipos de programas de protección social, incluidas las pensiones para el adulto mayor. Debido a que muchos de los pobres pertenecen al sector informal, carecen de acceso a las pensiones que otorgan los sistemas de seguridad social; asimismo, los situados en el sector informal carecen a menudo de acceso a otros beneficios organizados por el Estado, como la vivienda para los grupos de bajos ingresos (véase un análisis en torno a las pensiones para los pobres en Holzmann y Packard, 1999). 


\section{IV}

\section{Las restricciones: el espacio fiscal y la capacidad administrativa}

\section{1. ¿Los programas de protección social son anticíclicos?}

Los buenos programas de protección social deben expandirse durante una crisis económica a medida que crece el desempleo y disminuyen los niveles de ingreso. En otras palabras, deben ser de índole anticíclica, es decir, ampliarse cuando se contrae la economía. En algunos países, el sistema de redes de seguridad está apoyado por derechos automáticos a recibir prestaciones que obligan al sector público a gastar más en aquellos que lo necesitan. Por ejemplo, el desempleo provoca un incremento del número de personas con derecho a recibir indemnización por desempleo, y la declinación del ingreso puede acrecentar el número de hogares con derecho a recibir asistencia en efectivo o alimentaria. Pero en la mayoría de los países latinoamericanos no hay tales gatillos automáticos. Esto se explica en parte porque la necesidad de tener programas de protección social anticíclicos puede entrar en conflicto con la necesidad de imponer la austeridad fiscal durante una recesión. Una crisis económica, inducida en forma inter- na o externa, provoca una caída del producto, y en consecuencia una caída de los ingresos del gobierno. Pero durante la crisis los gobiernos son renuentes a aumentar los impuestos. Por lo tanto, la mantención de un alto nivel de gasto puede conducir a grandes déficit presupuestarios.

Considérense los datos presentados en el cuadro 4. Tanto Argentina como México sufrieron una perturbación adversa en 1995 (México primero, Argentina después). En Argentina el PIB per cápita disminuyó 5.32\% entre 1994 y 1995, mientras que en México cayó 4.93\% entre 1994 y 1996. La proporción del PIB destinada al gasto social focalizado disminuyó un poco y el índice de pobreza aumentó en ambos países, con lo cual se elevó el número total de personas pobres. El gasto focalizado por persona pobre disminuyó mucho más que el PIB per cápita, dando una elasticidad respecto al crecimiento (en este caso a una recesión) del gasto focalizado por persona pobre de alrededor de cinco en ambos países. Durante esta recesión, el gasto en los pobres fue por lo tanto altamente procíclico, aunque en teoría debería haber sido anticíclico a fin de protegerlos de la perturbación macroeconómica adversa.

CUADRO 4

Argentina y México: Gasto público focalizado por persona pobre, 1994-1996

\begin{tabular}{|c|c|c|c|c|c|}
\hline & $\begin{array}{l}\text { PIB real per cápita } \\
\quad(1994=100)\end{array}$ & $\begin{array}{l}\text { Proporción del gasto } \\
\text { social focalizado } \\
\text { respecto del PIB } \\
\text { (en porcentaje) }\end{array}$ & $\begin{array}{l}\text { Indice de pobreza } \\
\text { (en porcentaje) }\end{array}$ & $\begin{array}{l}\text { Número de } \\
\text { personas pobres } \\
\text { (en millones) }\end{array}$ & $\begin{array}{l}\text { Gasto focalizado } \\
\text { por persona pobre } \\
\quad(1994=100)\end{array}$ \\
\hline \multicolumn{6}{|l|}{ Argentina } \\
\hline 1994 & 100 & 1.24 & 21.6 & 7.5 & 100 \\
\hline 1995 & 94.68 & 1.21 & 27.2 & 9.6 & 63.12 \\
\hline $\begin{array}{l}\text { Variación } \\
\text { porcentual }\end{array}$ & $-5.32 \%$ & & & & $-27.88 \%$ \\
\hline \multicolumn{6}{|l|}{ México } \\
\hline 1994 & 100 & 1.36 & 46.95 & 42.04 & 100 \\
\hline 1996 & 95.07 & 1.23 & 60.93 & 56.51 & 67.30 \\
\hline $\begin{array}{l}\text { Variación } \\
\text { porcentual }\end{array}$ & $-4.93 \%$ & & & & $-23.70 \%$ \\
\hline
\end{tabular}

Fuente: Wodon, Hicks y otros (1999). Los datos para ambos países no son estrictamente comparables. Por tanto, no debe deducirse que el gasto en protección social es más procíclico en un país que en otro. Nótese asimismo que el Gobierno de México ha desplegado un esfuerzo considerable para incrementar el financiamiento focalizado en los pobres en el último año, por ejemplo, otorgando financiamiento a Progresa. Esto no está reflejado en el cuadro. 
Los datos del cuadro están b asados solamente en un período para dos países y en varios supuestos tanto para la estimación de la pobreza como para la categorización del gasto social. Sería engañoso concluir que la protección social disminuye en todos los países durante una crisis. Lamentablemente, más allá de estimaciones puntuales de las elasticidades del gasto focalizado respecto al crecimiento como las presentadas en el cuadro, la medida en que los países latinoamericanos han brindado protección social anticíclica es algo que ha recibido muy poca atención. Un problema es que los datos sobre el gasto presupuestario no suelen identificar la protección social o las redes de seguridad como una actividad separada. Los programas de protección social están dispersos en varios sectores, como salud, educación, seguridad social y bienestar. Sin embargo, en algunos países hay datos disponibles.

Wodon, Hicks y otros (1999) utilizan datos sobre siete países (Argentina, Bolivia, Chile, Costa Rica, México, Panamá y República Dominicana) para comprobar los efectos del ciclo económico en el gasto focalizado y el gasto social latinoamericano. Proponen primero un modelo teórico para analizar cómo el gasto público focalizado en los pobres puede verse afectado por auges y recesiones. Se dice que un gobierno es "pro pobres" si otorga una ponderación razonable a los pobres en su función de bienestar social, si considera que hay un nivel mínimo de necesidades esenciales de los pobres que deben satisfacerse, si eleva en el tiempo este nivel de necesidades esenciales con mayor rapidez que el PIB durante un período de crecimiento, y si no reduce el nivel de necesidades esenciales mínimas durante una recesión temporal. Si un gobierno es "pro pobres" según la definición mencionada, la elasticidad del gasto público focalizado respecto al crecimiento será positiva, y será mayor que uno durante los auges y menor que uno durante las recesiones. Si el gobierno no es "pro pobres", el modelo predice que la elasticidad del gasto focalizado será siempre menor o igual a uno. La existencia de una asimetría entre auges y recesiones en la elasticidad respecto al crecimiento del gasto público focalizado en los pobres cuando el gobierno es "pro pobres" se verifica luego con el conjunto de datos sobre el gasto público. Los resultados del cuadro 5 sugieren que los gobiernos son, hasta cierto punto, pro pobres y pro sociales dado que los gastos focalizado y social se están elevando con mayor rapidez que el PIB y el gasto total del gobierno durante los auges. Aunque esto es alentador, no es menos cierto que durante las recesiones el gasto focalizado no está protegido: decrece levemente más rápido que el PIB (aunque en el cuadro 5 las elasticida- des no son estadísticamente diferentes de uno en el caso de una recesión). Así, aunque pueda considerarse que los gobiernos son "pro pobres", el gasto social y focalizado sigue siendo altamente procíclico. Los datos sugieren que los programas de protección social, en vez de expandirse con rapidez durante una crisis, en realidad se contraen en muchos casos con tanta rapidez como otros tipos de gasto público. ${ }^{15}$

El impacto de una recesión sobre el gasto focalizado en los pobres es, incluso, más negativo que lo sugerido en el cuadro 5. Puede demostrarse que en América Latina la baja de un punto porcentual del PIB per cápita provoca al menos una disminución de dos puntos porcentuales del gasto público focalizado por persona pobre. La mitad de este efecto se debe a la reducción del propio PIB per cápita, que disminuye el gasto incluso cuando la proporción del gasto focalizado respecto al PIB permanece constante (el hecho de que la proporción permanece constante lo comprueba la elasticidad unitaria en el cuadro 5). La otra mitad del efecto proviene del aumento de la pobreza debido a la crisis, es decir, el gasto público focalizado disponible tiene que repartirse entre un mayor número de personas pobres.

El hecho de que los programas focalizados en los pobres no estén bien protegidos puede resultar extraño dado que estos programas representan una pequeña proporción del PIB (habitualmente $2 \%$ o menos), y también una pequeña proporción del gasto total. Una de las razones de la falta de protección del gasto focalizado estaría relacionada con la falta de poder negociador de los pobres. Otra razón de por qué sería

CUADRO 5

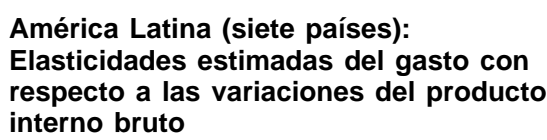

\begin{tabular}{lcc}
\hline & Crecimiento $^{\mathrm{a}}$ & Recesión \\
\hline Gasto total del gobierno & 0.971 & 1.003 \\
Gasto en los sectores sociales & $1.475^{*}$ & 1.128 \\
Gasto en protección social & $1.999 *$ & 1.391 \\
\hline
\end{tabular}

Fuente: Adaptado de Wodon, Hicks y otros (1999). Muestra de siete países, con 97 observaciones.

a $\mathrm{El} *$ denota una elasticidad estadísticamente diferente de uno a nivel de $5 \%$.

15 Ravallion (2000) llega a conclusiones similares con los datos relativos a Argentina. 
difícil proteger el gasto durante una crisis económica y fiscal es que el país tiene que cumplir con el servicio de la deuda y con varios programas que garantizan derechos, y dispone por consiguiente de recursos discrecionales relativamente escasos. En otras palabras, si 30\% del presupuesto está protegido para atender los aspectos vinculados con redes de seguridad y pobreza, y $50 \%$ se destina al servicio de la deuda y a otros programas que no pueden recortarse, una reducción de $10 \%$ del gasto total produciría una disminución del $50 \%$ en los sectores restantes. Dado que estos últimos podrían incluir áreas tan sensibles como defensa, justicia y administración pública, tal solución no sería viable, lo que obligaría al gobierno a abandonar la idea de resguardar el financiamiento de programas claves de protección social. De este análisis se desprende que la prevención frente a una crisis es decisiva, porque durante las crisis siempre será difícil proteger a los pobres.

\section{2. ¿Cómo seleccionar los programas que deben protegerse $o$ expandirse durante una crisis?}

El primer objetivo durante una crisis debe ser concordar en que los programas claves que benefician a los pobres no se recortarán aunque se reduzca el gasto total del gobierno. Enseguida debe encararse la difícil decisión de cuáles programas deben protegerse o incluso expandirse. Resulta tentador incluir en la lista casi todos los programas básicos de salud, educación y nutrición. Pero en los sectores sociales no todos los programas son igualmente eficaces para reducir la pobreza, y algunos que producen beneficios de largo plazo para los pobres podrían aplazarse. Para decidir qué programas mantener y expandir durante una crisis, un criterio importante debe ser el costo-eficacia del programa para canalizar rápidamente el ingreso, o su equivalente en especie, hacia los pobres. Tal como se sugirió en el caso de los programas de asistencia laboral, ese costo-eficacia depende de varios parámetros, y el hecho de conocer tales parámetros de antemano permite hacer una selección. La comparación del costo-eficacia de las redes de seguridad alternativas para proteger los patrones de consumo de los pobres mediante la generación de ingreso, la distribución de productos básicos en especie o el subsidio a los productos básicos es un área que requiere indudablemente una mayor labor analítica.

Uno de los elementos de una estrategia viable - en realidad, uno de los parámetros claves del costo-eficacia de las redes de seguridad- es la protección de los pro- gramas que cuentan con buenos mecanismos de focalización para llegar a los pobres. Los programas de bienestar universales o no focalizados suelen ser imposibles de sostener desde el punto de vista fiscal, sobre todo durante una crisis. Es cierto que la focalización de beneficiarios a través de una compleja verificación de sus medios de sustento (por ejemplo, el interrogatorio a fondo sobre el ingreso y la riqueza) puede ser costosa y no muy digna de fiar. Por ello es que muchos programas financiados por el Banco Mundial se han basado en la focalización geográfica, aunque esto puede conducir a una considerable filtración de recursos. Otro enfoque es la verificación de medios sustitutivos: los candidatos son entrevistados y responden a preguntas sobre sus niveles de vida, tales como el tipo de vivienda en que residen, la disponibilidad de agua, los tipos de artefactos que posee el hogar, etcétera. Wodon (1997) ha demostrado que estos indicadores son determinantes para evitar los dos tipos de errores que pueden cometerse en la focalización, a saber, identificar como pobre un hogar no pobre, y considerar no pobre un hogar pobre. Dentro de un presupuesto dado, la buena focalización sirve también para mejorar la cobertura entre los pobres (es decir, qué porcentaje de pobres reciben realmente los beneficios del programa), lo que es una ventaja importante en América Latina donde la cobertura a menudo ha sido baja.

Se han utilizado variantes de los sistemas de verificación de medios de sustento, entre otras, para la ficha del Comité de Acción Social en Chile (ficha CAS), el Sistema de Identificación de Beneficiarios ( SISBEN) en Colombia, el Sistema de Identificación único de Familias Beneficiarias ( SISFAM) en Argentina y Progresa en México. En la práctica, se entrevistan las personas que solicitan asistencia y el puntaje que arroja el cuestionario determina si reúnen los requisitos. Las ponderaciones para los diversos indicadores incluidos en el cuestionario están basadas en las relaciones econométricas estimadas entre la condición de pobreza de una muestra representativa de hogares y sus indicadores. Grosh (1994) ha estimado que el costo de la focalización mediante la verificación de medios sustitutivos o de la focalización geográfica (zonas pobres) no tiene por qué ser mucho más elevado que el costo de la distribución universal (un recargo razonable sería de $3 \%$ a $8 \%$ ), mientras que produciría beneficios considerables. En una muestra de programas no focalizados, sólo $33 \%$ de los beneficios llegaba al $40 \%$ de menores ingresos de la población, mientras que en los programas focalizados lo hacía el $72 \%$. 
Aparte de la necesidad de proteger el consumo de los pobres durante una crisis, queda claro también que deben preservarse algunos programas existentes en materia de salud y educación que no están focalizados necesariamente en los pobres. Es posible que la demanda de esos programas aumente si, por ejemplo, las pérdidas de ingreso debidas al desempleo o subempleo inducen a las personas a cambiarse de los prestadores privados y los seguros privados de salud a los programas públicos. En materia de salud, habrá que mantener algunos programas no focalizados en los pobres porque hay grandes externalidades involucradas (vigilancia epidemiológica, campañas de inmunización, control del paludismo, prevención del SIDA). La preservación del acceso a la enseñanza primaria y primer ciclo de la secundaria no compete a una red de seguridad de corto plazo. Pero cabe recordar que reduce los costos de una crisis en el largo plazo, pues evita recortes del gasto en educación de los pobres que conducirían, en definitiva, a una reducción del capital humano y provocarían con ello menores productividad e ingreso.

Para proteger todos los programas descritos, habrá que identificar los que puedan reducirse, suspenderse o eliminarse. Por ejemplo, algunos de los peores ejemplos de malgasto social en América Latina han sido los grandes programas de vivienda subvencionada para la clase media, dispuestos a menudo mediante impuestos específicamente asignados. Aunque tal vez sea imposible que un gobierno cambie sus programas con rapidez sin la intervención de una alta autoridad legislativa o incluso constitucional, en algunos casos la necesidad de reasignar el gasto debido a una emer- gencia o una crisis puede facilitar la introducción de cambios fundamentales. Otros candidatos a verse afectados por la reducción del gasto podrían ser los subsidios involucrados, por ejemplo, en la fijación de precios bajo el costo para grupos no pobres en los servicios de electricidad, agua o transporte urbano. También podría contribuir una mejor recuperación del costo de la educación superior (por ejemplo, a nivel universitario) y de algunos servicios de atención de salud. El cuadro 6 (ideado a partir de una discusión con K. Lindert) ofrece un orden de prelación genérico basado en la práctica y observación común, aunque las prioridades pueden variar de un país a otro.

\section{Problemas adicionales de implementación}

Hay varios problemas adicionales que deben considerarse cuando se implementan redes de seguridad. Primero, es difícil establecer nuevas instituciones que funcionen con eficacia a nivel nacional. La mayoría de los fondos sociales, por ejemplo, tardan dos a tres años en comenzar a operar a un nivel que les permita llegar a un número considerable de personas pobres. Cuando el tiempo apremia, es mucho más fácil trabajar con las instituciones existentes, prestándoles apoyo para expandir sus operaciones durante una crisis. A menudo, también es posible ampliar los programas de redes de seguridad ya iniciados de manera experimental, que han sido evaluados y su eficacia comprobada. Como corolario, convendría experimentar de vez en cuando con nuevos programas, para justipreciar sus fortalezas y debilidades y su capacidad de expandirse en caso

CUADRO 6

Las prioridades en la protección de programas durante las crisis: un orden de prelación posible

\begin{tabular}{|c|c|c|c|}
\hline & Salud & Educación & Protección social/otros \\
\hline Prioridad alta & $\begin{array}{l}\text { Inmunizaciones } \\
\text { Lucha contra las enfemedades } \\
\text { Prevención del SIDA } \\
\text { Atención del embarazo y desarrollo } \\
\text { del niño en la primera infancia }\end{array}$ & $\begin{array}{l}\text { Estipendios sujetos a verificación } \\
\text { de medios } \\
\text { Desayuno escolar en zonas pobres } \\
\text { Programas especiales para las } \\
\text { zonas indígenas }\end{array}$ & $\begin{array}{l}\text { Programas de asistencia laboral } \\
\text { Pensiones para los ancianos sujetas } \\
\text { a verificación de medios de } \\
\text { sustento } \\
\text { Suplementos nutricionales sujetos a } \\
\text { verificación de medios de sustento }\end{array}$ \\
\hline $\begin{array}{l}\text { Prioridad } \\
\text { moderada }\end{array}$ & $\begin{array}{l}\text { Postas y centros primarios de } \\
\text { atención de salud } \\
\text { Atención básica en hospitales }\end{array}$ & $\begin{array}{l}\text { Educación primaria y primer ciclo } \\
\text { de la secundaria } \\
\text { Becas para estudiantes pobres en } \\
\text { las universidades }\end{array}$ & $\begin{array}{l}\text { Seguros de desempleo } \\
\text { Seguridad social } \\
\text { Fondos sociales } \\
\text { Capacitación laboral } \\
\text { Subsidios alimentarios }\end{array}$ \\
\hline Prioridad baja & $\begin{array}{l}\text { Atención curativa avanzada en } \\
\text { hospitales }\end{array}$ & $\begin{array}{l}\text { Educación universitaria gratuita a } \\
\text { bajo costo para los no pobres } \\
\text { Presupuestos de investigación }\end{array}$ & $\begin{array}{l}\text { Vivienda subvencionada } \\
\text { Subsidios para servicios de } \\
\text { infraestructura }\end{array}$ \\
\hline
\end{tabular}


necesario. Asimismo, se podrían utilizar las instituciones existentes encargadas de programas de capacitación laboral, fondos sociales o transferencias para distribuir asistencia de emergencia en caso de necesidad.

Segundo, no todos los gobiernos poseen la misma capacidad para administrar programas. En algunos países, un programa sencillo que no esté bien focalizado puede ser una opción mejor que un programa más complejo. Los programas de redes de seguridad tienen que encontrar el justo equilibrio entre capacidad administrativa, sustentabilidad fiscal, aceptabilidad política, cobertura de la intervención y eficiencia en la focalización. Otro problema es la relación entre el gobierno nacional o federal y el provincial. El personal de los bancos de fomento multilaterales ha establecido tradicionalmente un diálogo con las autoridades nacionales o federales, pero gran parte del gasto social ocurre a nivel provincial. Sería necesario convenir un apoyo adicional del presupuesto federal a los presupuestos estaduales, provinciales o municipales durante una crisis, en caso de que los programas de redes de seguridad se ejecuten a nivel local. Sin embargo, aunque la descentralización tiene varias ventajas, ésta no es necesariamente "pro pobres", de modo que se precisa una supervisión cabal de las autoridades subnacionales.

Tercero, un problema que existe en muchos países es la proliferación de pequeños programas en di-

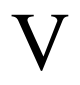

\section{Conclusiones}

Las perturbaciones económicas pueden conducir a una declinación del ingreso real causada por una pérdida de empleo, una situación de subempleo o un cambio a un empleo menos lucrativo. Los salarios reales pueden reducirse también debido a altos niveles de inflación. Las variaciones de los precios relativos pueden tener efectos negativos. Los pobres pueden perder también su acceso a los servicios públicos esenciales de salud, nutrición y educación como resultado de un menor gasto real del gobierno. Pueden perder el valor de sus activos financieros (por magros que sean) si éstos no están protegidos de la quiebra por el sistema financiero o por el sistema público de seguridad social. O simplemente tal vez tengan que vender esos activos. Ante todos estos efectos potenciales y muchos otros, los pobres son más vulnerables que los no pobres porque versas instituciones del gobierno. Los programas de nutrición, por ejemplo, figuran en los ministerios de salud, educación, desarrollo social y agricultura, así como en los organismos autónomos adscritos a la oficina de la presidencia. Los programas de capacitación están a cargo de los ministerios de educación, trabajo y desarrollo económico. Es importante establecer alguna especie de coordinación interministerial para evitar las superposiciones y duplicaciones. En el largo plazo, se podría combinar o consolidar los programas y eliminar los que sean menos eficaces. Cabe recordar que una crisis puede servir para reorientar los presupuestos sociales.

Cuarto, al supervisar los niveles de gasto es preferible, en principio, utilizar el gasto real y no los montos presupuestados. Sin embargo, en muchos países es difícil hacer un seguimiento de los niveles reales de gasto debido al considerable rezago con que se recibe la información. Cuando se llega a saber que el gasto real ha disminuido o que los créditos disponibles no se han utilizado, podría ser demasiado tarde. Para evitar los recortes presupuestarios involuntarios debido a desfases en el gasto es importante, una vez efectuadas las asignaciones, desplegar algunos esfuerzos para asegurar que los presupuestos se establecen operacionalmente y se mantienen a niveles adecuados, con un seguimiento continuo del gasto, de manera que los planes se ejecuten realmente. su ingreso puede caer con mucha mayor rapidez bajo los niveles de la mera subsistencia.

Es una práctica habitual recomendar que los gobiernos resguarden los programas claves de protección social durante las crisis y expandan la red de seguridad social. No obstante, con los recursos fiscales contrayéndose en momentos en que el número de pobres está creciendo, sería extremadamente difícil hacerlo. Con todo, cabría esperar al menos que los programas de alta prioridad estuvieran menos sujetos a recortes que otros, ya que las redes de seguridad social representan sólo una pequeña parte de los presupuestos. Sin embargo, éste no parece ser el caso actualmente. En vez de ser anticíclicas, las redes de se guridad son tan procíclicas como otros tipos de gasto público, y en algunos casos pueden ser de hecho más procíclicas. Lo 
paradójico es que el propio gasto en protección social no está protegido.

Suponiendo que hay un acuerdo de proteger a los pobres contra los recortes presupuestarios durante una crisis, la pregunta pasa a ser: ¿qué programas deben protegerse? No hay respuestas fáciles a esta pregunta, y las que se den dependerán del país de que se trate. Con todo, un criterio importante para seleccionar los programas que deben protegerse o expandirse es la capacidad para entregar rápidamente a los pobres un complemento de su ingreso o su equivalente en especie. La asistencia laboral puede ser útil, pero las autoridades deben tener conciencia de que suele costar más de tres dólares generar un dólar adicional de ingresos netos para los pobres con estos programas. También pueden ser útiles algunos programas nutricionales y alimentarios que estén bien focalizados, lo que no siempre ocurre. La buena focalización es uno de los parámetros claves del costo-eficacia de las redes de seguridad. Asimismo, los programas sociales existentes que no constituyen redes de seguridad propiamente tales (por ejemplo, programas de capacitación labo- ral, fondos sociales y estipendios condicionados a la asistencia escolar en zonas pobres) pueden ser mecanismos valiosos para prestar asistencia de emergencia cuando hay una capacidad administrativa limitada en el país. Aparte de compensar a los pobres por la pérdida probable en el ingreso de mercado que ocurre durante una crisis, también es necesario que el gobierno proteja algunos programas universales, como la atención primaria de salud, la enseñanza primaria y los programas de salud con grandes externalidades. Pero la tarea más difícil es la de identificar los programas que pueden reducirse, suspenderse o eliminarse. Entre ellos estarían la vivienda subvencionada, otros subsidios a productos no consumidos principalmente por los pobres, algunos programas de seguridad social y el gasto en educación superior y atención de salud curativa avanzada. Aunque suele ser políticamente difícil reformar estos programas, la necesidad de actuar en época de crisis puede facilitar la introducción de los cambios fundamentales necesarios.

(Traducido del inglés)

APENDICE

Principales riesgos por grupo etario y papel de la protección social en el enfrentamiento de esos riesgos

\begin{tabular}{|c|c|c|c|c|}
\hline $\begin{array}{l}\text { Grupo } \\
\text { etario }\end{array}$ & Riesgos principales & Papel de otros sectores & $\begin{array}{l}\text { Papel de la protección } \\
\text { social: seguros }\end{array}$ & $\begin{array}{l}\text { Papel de la protección } \\
\text { social: asistencia }\end{array}$ \\
\hline $0-4$ & - Retraso del crecimiento infantil & $\begin{array}{l}\text { - Servicios primarios de salud } \\
\text { - Centros preescolares }\end{array}$ & - & $\begin{array}{l}\text { - Desarrollo del niño en la } \\
\text { primera infancia }\end{array}$ \\
\hline $5-14$ & $\begin{array}{l}\text { - Educación de mala calidad } \\
\text { - Ingreso tardío a la escuela } \\
\text { - Mayor edad de la } \\
\text { correspondiente al grado }\end{array}$ & $\begin{array}{l}\text { - Educación de calidad } \\
\text { - Ingreso más temprano } \\
\text { - Menor repitencia }\end{array}$ & - & $\begin{array}{l}\text { - Becas e incentivos } \\
\text { escolares }\end{array}$ \\
\hline $15-24$ & $\begin{array}{l}\text { - Bajas tasas de conclusión de la } \\
\text { enseñanza secundaria } \\
\text { - Embarazo adolescente } \\
\text { - Enfermedades de transmisión } \\
\text { sexual }\end{array}$ & $\begin{aligned} & \text { - } \text { Acceso/calidad de la } \\
& \text { enseñanza secundaria } \\
& \text { - Educación correctiva } \\
& \text { - Salud reproductiva }\end{aligned}$ & - & $\begin{array}{l}\text { - Becas e incentivos } \\
\text { escolares }\end{array}$ \\
\hline $65+$ & $\begin{array}{l}\text { - Bajos ingresos } \\
\text { (sin pensión, sin activos) }\end{array}$ & & $\begin{array}{l}\text { - Seguridad social } \\
\text { (pensiones por afiliación) }\end{array}$ & $\begin{array}{l}\text { - Transferencia de ingresos } \\
\text { (pensiones sin afiliación) }\end{array}$ \\
\hline $\begin{array}{l}\text { Todos } \\
\text { los grupos }\end{array}$ & $\begin{array}{l}\text { - Poco acceso a la atención de } \\
\text { salud y mala calidad de ella } \\
\text { - Vivienda de mala calidad } \\
\text { - Poco acceso a la infraestructura } \\
\text { básica } \\
\text { - Dominio inseguro del predio } \\
\text { - Riesgo de inundaciones }\end{array}$ & $\begin{array}{l}\text { - Mejor provisión de } \\
\text { servicios de salud } \\
\text { - Vivienda accesible } \\
\text { - Inversiones en } \\
\text { infraestructura básica } \\
\text { - Programas de otorgamiento } \\
\text { de títulos de dominio }\end{array}$ & - Seguro de salud & $\begin{array}{l}\text { - Subsidios a la vivienda } \\
\text { - Traslado a zonas seguras }\end{array}$ \\
\hline
\end{tabular}

Fuente: Adaptado de Arriagada (1999). 


\section{Bibliografía}

Arriagada, A.M. (1999): Managing social risk in Argentina, Washington, D.C., Banco Mundial.

Banco Mundial (1999): Social protection sector strategy paper, Washington, D.C.

Basu, K. y P. H. Van (1998): The economics of child labor, The American Economic Review, vol. 88, No 3, Nashville, Tennessee, American Economic Association.

Besley, T. y R. Kanbur (1988): Food subsidies and poverty alleviation, The Economic Journal, vol. 98, No 392 , Oxford, Reino Unido, Basil Blackwell.

(1993): The principles of targeting, M. Lipton y J. Van der Gaag (eds.), Including the Poor, Washington, D.C., Banco Mundial.

Castro-Fernández R. y Q. Wodon (2000): Protecting the unemployed in Chile: From state assistance to individual insurance, Washington, D.C., Banco Mundial.

Cornia, G. A. y F. Stewart (1995): Two errors of targeting, en D. Van de Walle y K. Nead (eds.), Public Spending and the Poor: Theory and Evidence, Baltimore, Pennsylvania, Johns Hopkins University Press.

Cunningham, W. (1998): Breadwinner versus care giver: Labor force participation and sectoral choice over the Mexican business cycle, Washington, D.C., Banco Mundial.

Dall'Acqua, F. (1991): Economic adjustment and nutrition policies: Evaluation of a school-lunch programme in Brazil, Food and Nutrition Bulletin, vol. 13.

Dar, A. y Z. Tzannatos (1999): Active Labor Market Programs: A review of the Evidence from Evaluations, Social protection discussion paper $N^{\circ} 9901$, Washington, D.C., Banco Mundial.

De Ferranti, D., G. E. Perry y otros (2000): Securing our Future in a Global Economy, Washington, D.C., Banco Mundial.

De Janvry, A. y E. Sadoulet (1999): Growth, poverty, and inequality in Latin America: A causal analysis 1970-1994, Washington, D.C., Banco Interamericano de Desarrollo (BID).

ESA Consultores (1999): Evaluación ex-post del Fondo Hondureño de Inversión Social, Tegucigalpa.

Ezemenari, K. (1997): The link between public and private interhousehold transfers: Implications for the design of safety net programs in developing countries, American Journal of Agricultural Economics, vol. 79, Ames, Iowa, Asociación de Latinoamérica y del Caribe de Economistas Agrícolas (ALACEA).

Ezemenari, K. y K. Subbarao (1999): Social Assistance and PovertyTargeted Programs: A Toolkit for Latin America and the Caribbean, Washington, D.C., Banco Mundial.

Fajnzylber, P. and W. Maloney (1999): Labor demand and trade reform in Latin America, Washington, D.C., Banco Mundial.

Ganuza, E., L. Taylor y S. Morley (1998): Política macroeconómica y pobreza en América Latina y el Caribe, Madrid, Ediciones Mundi-Prensa.

Gill, I. (1999): Managing socioeconomic risks in Latin America and the Caribbean, Washington, D.C., Banco Mundial.

Glewwe, P. y G. Hall (1998): Are some groups more vulnerable to macroeconomic shocks than others? Hypothesis tests based on panel data from Peru, Journal of Development Economics, vol. 56, No 1, Amsterdam, Países Bajos, Elsevier Science Publishers, B.V.

Goodman, M., S. Morley y otros (1997): Social Funds in Latin America: Past Performance and Future Role, Washington, D.C., BID.

Grosh, M. E. (1992): The Jamaican food stamps programme, Food Policy, vol. 17, Stoneham, Massachusetts, Butterworth-Heinemann, Ltd.

(1994): Administering Targeted Social Programs in Latin America: From Platitudes to Practice, Washington, D.C., Banco Mundial.
(1995): Five criteria for choosing among poverty programs, en N. Lustig (ed.), Coping with Austerity: Poverty and Inequality in Latin America, Washington, D.C., Brookings Institution.

Hicks, N. (1991): Expenditures reductions in developing countries revisited, Journal of International Development, vol. 3, $\mathrm{N}^{\mathrm{o}} 1$, West Sussex, Reino Unido, John Wiley \& Sons, Ltd.

Holzmann, R. y S. Jorgensen (1999): Social protection as social risk management: Conceptual underpinnings for the social protection strategy paper, Social protection discussion paper, $\mathrm{N}^{\circ}$ 9904, Washington, D.C., Banco Mundial.

Holzmann, R. y T. Packard (1999): Extending coverage in multipillar pension systems: Constraints and hypotheses, preliminary evidence and future research agenda, Washington, D.C., Banco Mundial.

Jacoby, E., S. Cueto y E. Politt (1996): Benefits of a school breakfast programme among Andean children in Huaraz, Peru, Food and Nutrition Bulletin, vol. 17.

Jalan, J. y M. Ravallion (1998): Income gains from workfare and their distribution: Estimates from Argentina's Trabajar program, Washington, D.C., Banco Mundial.

Jorgensen, S., M. Grosh y M. Schacter (1992): Bolivia's Answer to Poverty, Economic Crisis and Adjustment: The Emerging Social Fund, Washington, D.C., Banco Mundial.

Karni, E. (1999): Optimal unemployment insurance: A guide to the literature, Social protection discussion paper, $N^{\circ}$ 9906, Washington, D.C., Banco Mundial.

Klugman, J. (1999): Social safety nets and crises, Washington, D.C., Banco Mundial.

Levy, S. y E. R. Dávila (1998): Subsidios y política social, Examen, vol. 110.

Lustig, N. (ed.) (1995): Coping with Austerity: Poverty and Inequality in Latin America, Washington, D.C., The Brookings Institution.

(1999): Crisis and the Poor: Socially Responsible Macroeconomics, Presidential address to LACEA 1999, Washington, D.C., The Brookings Institution.

Lustig, N. y O. Arias (por publicarse): Poverty and inequality in Latin America: Economic crises and widening returns to skills, Finance and Development, Washington, D.C., Fondo Monetario Internacional (FMI).

Maloney, W. (2000): The evaluation of workfare and conditional transfer programs as emergency measures, and a modification to Trabajar, Washington, D.C., Banco Mundial.

Nickell, S. (1997): Unemployment and labor market rigidities: Europe versus North America, The Journal of Economic Perspectives, vol. 1, $\mathrm{N}^{\circ} 3$, Nashville, Tennessee, American Economic Association.

Phillips, M., G. Sáenz y otros (1995): The Costs and Cost-Effectiveness of School Feeding and School Bonos Programs in Honduras, Informe N ${ }^{\circ}$ LAC-0657-C-00-0051, Washington, D.C., Agencia de los Estados Unidos para el Desarrollo Internacional (USAID).

Pradhan, M., L. Rawlings y G. Ridder (1998): The Bolivian social investment fund: An analysis of baseline data for impact evaluation, The World Bank Economic Review, vol. 12, N 3 , Washington, D.C., Banco Mundial.

Progresa (Programa de Educación, Salud y Alimentación) (1999): Más oportunidades para las familias pobres, México, D.F.

Ravallion, M. (1999): Appraising workfare, The World Bank Research Observer, vol. 14, Washington, D.C., Banco Mundial.

(2000): On protecting the poor from fiscal contractions, Washington, D.C., Banco Mundial. 
Ravallion, M. y Q. Wodon (2000a): Does child labor displace schooling? Evidence on behavioral responses to an enrollment subsidy, The Economic Journal, vol. 110, Oxford, Reino Unido, Basil Blackwell, marzo.

(2000b): Banking on the poor? Branch placement and nonfarm rural development in Bangladesh, Review of Development Economics, $\mathrm{N}^{\circ} 4$.

Revenga, A., M. Riboud y H. Tan (1994): The impact of Mexico's retraining program on employment and wages, The World Bank Economic Review, vol. 8, No 2, Washington, D.C., Banco Mundial.

Rodrik, D. (1999): Why is there so much insecurity in Latin America?, Boston, Harvard University.

Sahn, D. y H. Alderman (1995): Incentive effects on labor supply of Sri Lanka's rice subsidy, en D. Van de Walle y K. Nead (eds.), Public Spending and the Poor: Theory and Evidence, Baltimore, Pennsylvania, Johns Hopkins University Press.

Skoufias, E., B. Davis y J. Behrman (2000): Evaluación del sistema de selección de familias beneficiarias, Progresa, Progresa, más oportunidades para las familias pobres, México, D.F.

STPS (Secretaría de Trabajo y Previsión Social) (1998): Evaluación del programa de becas de capacitación para desempleados, México, D.F.

Subbarao K., A. Bonnerjee y otros (1997): Safety Net Programs and Poverty Reduction: Lessons from Cross-Country Experience, Washington, D.C., Banco Mundial.

Tuck, L. y K. Lindert (1996): From universal food subsidies to a self-targeted program: A case study in Tunisian reform, World Bank discussion paper, $\mathrm{N}^{\mathrm{o}} 351$, Washington, D.C., Banco Mundial.
Universidad de Chile (1992): Estudio sobre los programas especiales de empleo, Santiago de Chile, Departamento de Economía.

Wodon, Q. (1997): Targeting the poor using ROC curves, World Development, vol. 25, Washington. D.C., The American University.

(2000a): Poverty and policy in Latin America and the Caribbean, World Bank technical paper, $\mathrm{N}^{\circ} 467$, Washington, D.C., Banco Mundial.

(2000b): Public works employment and workfare programs: Optimizing the timing of benefits for poverty reduction, Washington, D.C., Banco Mundial.

Wodon, Q., G. González y C. Siaens (2000): Do conditionalities in social programs exclude the poorest? Demand-side schooling interventions in Latin America, Washington, D.C., Banco Mundial.

Wodon, Q., N. Hicks y otros (1999): Are governments pro-poor? A test based on targeted and social spending during booms and busts, Washington, D.C., Banco Mundial.

Wodon, Q. y M. Minowa (1999): Training the urban unemployed: A reevaluation of Mexico's probecat, Washington, D.C., Banco Mundial.

Wodon, Q. y C. Siaens (1999a): Child labor and government programs in Mexico, Washington, D.C., Banco Mundial.

(1999b): Food subsidies and consumption inequality in Mexico, Washington, D.C., Banco Mundial.

(2000): Estimating the cost of child labor, Washington, D.C., Banco Mundial.

Wodon, Q. y S. Yitzhaki (2000): Targeted social programs, allocation among beneficiaries, and income inequality, Washington, D.C., Banco Mundial. 